\title{
UN LÍDER DE LA REVOLUCIÓN HAITIANA EN CÁDIZ
}

\author{
JORGE ViCTORIA OJEDA \\ Archivo General del Estado de Yucatán
}

\section{RESUMEN}

En el artículo se narra la historia de un líder de la revolución haitiana en su fase de inicio (17911793) y después aliado de España en su lucha contra Francia por el control de la isla de Santo Domingo (1793-1795). Al término del conflicto Juan Francisco y parte de su tropa fue enviada a Cádiz, donde falleció en 1805, y a su gente se le permitió regresar a América hasta 1813. El autor saca a la luz a un olvidado personaje y destaca la manipulación a que fueron sometidos por la Corona después de haberles prometido la libertad y otros beneficios. La presencia de esos negros en la ciudad no pasó desapercibida para los diputados de las Cortes quienes utilizaron su nombre de acuerdo a sus intereses.

Palabras clave: Revolución haitiana, tropas de negros, Auxiliares, Cádiz, Juan Francisco.

\section{ABSTRACT}

In the article is narrated the history of a leader of the Haitian revolution in its beginning phase (1791-1793) and later ally from Spain in its fight against France for the control of Santo Domingo's island (1793-1795). At the end of the conflict Juan Francisco and part of their troops went remited to Cadiz, where he died in 1805 . To the other people was allowed to return to America in 1813. The author takes out to the light to a forgotten black celebrity and the manipulation to they were subjected by the Crown after having them highlights engaged the freedom and other benefits. The presence of those troops of blacks in the city didn't pass desapercibida for the deputies of the Cortes who used its name according to its interests.

Key words: Haitian revolution, troops of blacks, Auxiliaries, Cadiz, Juan Francisco.

\section{INTRODUCCIÓN}

Después de tres lustros de haberse enviado a Cádiz a un grupo de negros Auxiliares procedentes de Santo Domingo que lucharon en los inicios de la revolución haitiana (1791-1793) 
y después en el bando hispano en aquella Isla (1793-1795), don Vicente Terrero, diputado gaditano a Cortes, en su intervención del 5 de septiembre de 1811 cuando se discutía el artículo 22 de la Constitución referente a la ciudadanía española, recordó el hecho de la siguiente manera:

“(...) Ruego a V.S. no incurra en tales injusticias, para que no se reproduzcan aquellos tristes ejemplares de que cuando se me remueve la memoria siento en el alma una emoción muy terrible. Cuando los insignes negros de Santo Domingo, aquellos 63.000 hombres, se decidieron por la Patria española, y por ella derramaron espontáneamente su sangre, conducida su plana mayor á esta ciudad, se les despojó de su libertad, de sus títulos, de sus honores. ¿Y por que? (...)”.

Terrero se refería al grupo de Juan Francisco (Jean François), uno de los principales herederos del movimiento de negros de Saint-Domingue y posterior aliado de la Corona en sus fallidos intentos por reconquistar la parte occidental de La Española. ${ }^{2}$ Los vaivenes de este personaje por los bandos monárquicos francés e hispano, ocasionaron que las historias haitiana y española hayan casi borrado su paso por las páginas escritas del levantamiento de esclavos y del conflicto franco-hispano. No obstante, el miedo a los haitianos -a éstos y al propio alzamiento de esclavos y su repercusiónse mantuvo como un latente contagio revolucionario, aunque con el tiempo se convirtió en una referencia como factor de manipulación por parte de las elites, más que una influencia. ${ }^{3}$

A pesar de ese olvido en la historia, paradójicamente algunos investigadores han dedicado algunas líneas para señalar, la mayoría sin fundamento, la fecha y lugar de la muerte de Juan Francisco.

\section{EL LEVANTAMIENTO DE ESCLAVOS}

El jefe del alzamiento de esclavos de agosto de 1791 era un negro jamaicano conocido como Boukman. A los pocos meses, al ser éste asesinado, la responsabilidad del movimiento recayó principalmente en Jean François y Georges Biassou, llamados por los españoles Juan Francisco y Jorge, respectivamente. Seguidos por miles de esclavos y cimarrones, esos negros incendiaron, principalmente, la parte norte de la colonia francesa. ${ }^{4}$

Al conocerse los acontecimientos de Saint-Domingue, Francia se apresuró a enviar en noviembre de 1791 a los Comisarios Mirbeck, Roume y Saint-Leger para tratar de buscar solución al conflicto. ${ }^{5}$ Incluso, tocó oportunidad a Juan Francisco y Biassou de ofrecer la paz a los franceses a cambios de dejar en libertad a varios centenares de prisioneros negros, asunto que no tuvo éxito. ${ }^{6}$

Diario de Sesiones de las Cortes Generales y Extraordinarias, 1810-1814, Madrid, 1810 Sesión del día 11 de septiembre de 1811, págs. 1777-1778.

2 Sobre este personaje, ver, VICTORIA OJEDA, Jorge: Tendencias monárquicas en la revolución haitiana. El negro Francisco Petecou bajo las banderas francesa y española, México, Siglo XXI Editores-Universidad de Quintana RooUNESCO, 2005.

3 THIBAUD, Clément: "Coupé têtes, brûle cazes. Temores y deseos de Haití en el Caribe hispánico", Visiones y Revisiones de la Independencia Americana. México, Centroamérica y Haití, (2005) págs. 110-113. CHUST, Manuel: La cuestión nacional americana en las Cortes de Cádiz, Valencia, UNED-Fundación Instituto de Historia Social-UNAM, 1999, págs. 102-111, apunta que "el fantasma de Haitî" estuvo muy presente en las Cortes cuando se discutieron temas de esclavitud, tráfico negrero y ciudadanía.

4 JAMES, C.L.R: Los jacobinos negros. Toussaint L'Ouverture y la Revolución de Haití, Madrid, Fondo de Cultura Económica, 2003, págs. 91, 98; FRANCO, José Luciano: Revoluciones y conflictos internacionales en el Caribe, 1789-1854, La Habana, Academia de Ciencias de Cuba, 1965, pág. 21.

5 FRANCO, José Luciano: Historia de la revolución de Haití, Santo Domingo, Editora Nacional, 1971, págs. 222-225.

${ }_{6}$ JAMES: Los jacobinos negros, págs. 107-110. 
En 1793, después de varias infructuosas peticiones de ayuda material por parte de los negros a Joaquín García, gobernador de Santo Domingo, y aprovechando la situación generada por los sucesos en la metrópoli francesa desde 1789 y en su colonia caribeña de Saint-Domingue, el 22 de febrero el rey Carlos IV de España envió una Real Orden a García en la que mandaba relacionarse con Juan Francisco, Biassou, Jacinto y demás cabecillas con el fin de ganarlos como aliados, prometiéndoles "libertad excepciones, goces y prerrogativas", y que el soberano los recibiría como vasallos suyos. A cambio de ello, los negros se dedicarían a atacar y hostilizar a la tropa y residentes de la colonia vecina, hasta que la Corona recuperase la totalidad de la Isla. ${ }^{7}$ La instrucción fue enviada con alevosía ya que a pesar de no haber guerra contra Francia en ese momento, se consideró que al llegar a manos de García el conflicto ya estuviese declarado.

La alianza se logró en los primeros meses de ese año recibiendo los negros el nombre de Tropas Auxiliares de Carlos IV, aunque en la documentación se les señala simplemente como Auxiliares de Santo Domingo, Auxiliares, o Negros franceses. ${ }^{8}$

No obstante las nuevas fuerzas con los que los españoles contaron y de los logros ante el enemigo hasta 1794, las aspiraciones de los hispanos y negros se frustraron debido al triunfo de los franceses en ese conflicto bélico. Gran parte del éxito de Francia se debió al pase de Toussaint Louverture a sus filas al mando de miles de seguidores después de que la Convención se comprometiera a abolir la esclavitud. La derrota española quedó oficializada con el Tratado de Paz de Basilea, en 1795, quedando la totalidad de La Española en manos de la nación vencedora. Francia solicitó a los hispanos la salida de la isla de sus antiguos aliados negros por considerar su presencia como un peligro latente para la seguridad de la misma. Ante esa petición España no tuvo otra salida que depurar sus tropas Auxiliares tratando de evacuar únicamente a los principales. ${ }^{9}$

El gobernador de Santo Domingo mandó a los evacuados a La Habana en dos viajes, encabezando Biassou el primero de ellos. Luis de las Casas y Aragorri, Capitán general de Cuba y gobernador de la Habana, al conocer las intenciones de envío se mostró renuente a la aceptación de esos negros por considerarlos sujetos de peligro por sus ideas de libertad y por el riesgo de contagio hacia los esclavos de la isla. ${ }^{10}$ Pero ante su inminente llegada, y después de formar una Junta para tomar la decisión de qué hacer con ellos, se determinó dividirlos en grupos y remitirlos a diversas partes del territorio español en América y a Cádiz. De tal forma, Jorge Biassou, acompañado de una veintena de personas, la mayoría familiares, fue mandado a tierras de la Florida; el líder Juan Francisco fue enviado a Cádiz, con más de un centenar de personas, y sus tropas fraccionadas en grupos y remitidas a Campeche, Trujillo, Portobelo, Isla de Trinidad, aunque el gobernador de ésta, José Chacón, no los aceptó y los mandó de nuevo a Santo Domingo."

Archivo General de Simancas. Secretaría de Guerra (en adelante, AGS. S.G.) leg.7157, exp.19, No,117. El gobernador d Santo Domingo contesta la Real Orden de 22 de febrero. Santo Domingo a 25 de abril de 1793.

8 Los Auxiliares no formaron parte del ejército aunque fueron de gran ayuda como líneas primarias de ataque. Sin embargo, su historia es peculiar ya que algunos tenían grado militar autoasignado que España les respetó, e incluso les sirvieron para seguir obteniendo alguna ayuda económica cuando salieron de Santo Domingo. Además gozaban de un sueldo pagado por la Corona. Debido a eso y al importante papel que jugaron en la guerra franco-hispana, es de llamar la atención que no se haga mención alguna de ellos en estudios referentes a la milicia o el Ejército, por ejemplo: KUETHE, Allan y MARCHENA Juan. Soldados del Rey. El ejército borbónico en América colonial en vísperas de la Independencia, Castellón, Universitat Jaume I, 2005.

9 Archivo Histórico Nacional (en adelante, AHN.) Estado, leg.3407. Esteban Laveaux general y gobernador de Santo Domingo a la Diputación de la República Francesa. Fuerte Delfín a 22 de noviembre de 1795; AHN. Estado, leg. 3407. Correspondencia del gobernador de Santo Domingo Joaquín García. Santo Domingo a 26 de noviembre de 1795.

10 Los problemas ocasionados por el envío de los negros a Cuba pueden verse en VICTORIA OJEDA, Jorge: "Tensión en el Caribe Hispano. Los negros ladinos de La Española en La Habana”, La excepción americana, (2005) págs. 111-127.

11 Sobre estos grupos ver, VICTORIA OJEDA, Jorge: De "Libertad, excepciones, goces y prerrogativas". Impulso y dispersión de las Tropas Auxiliares de rey de España en la guerra de Santo Domingo (1793-1848), Tesis Doctoral, Departament d'Història, Geografia i Art, Universitat Jaume I, 2005, capítulos IV al IX. 


\section{ENVÍO Y ESTANCIA DE LOS NEGROS AUXILIARES EN CÁDIZ}

La Península no significó para los integrantes de la Junta habanera problema alguno para el envío de la parte más destacada de las Tropas Auxiliares, pues no consideraron probable el contagio de la idea de libertad que, se decía, llevaban consigo los negros procedentes de SaintDomingue ya que la presencia mayoritaria de gente de color era de negros libres. La esclavitud en el siglo XVIII constituyó en España un fenómeno residual y en franco retroceso y todo apuntaba hacia su desaparición, sobre todo en la agricultura. De los recelos contra los vecinos, la reciente paz con Francia atenuaron las medidas tomadas contra los franceses residentes en el suelo peninsular. ${ }^{12}$ De todas maneras, tal como se señaló también en los casos de los otros envíos de Auxiliares, el sitio de destino se decía provisional.

Tras la llegada de la tropa de Juan Francisco a aguas habaneras y su división, Las Casas y Aragorri, sin conocer aun una orden del soberanol que prevenía lo contrario, mandó preparar las naves para su conducción a Cádiz. El líder negro y algunos de sus segundos en el mando fueron transportados al puerto gaditano en los navíos reales Santiago la España, en el que embarcaron también Watabe y Lefebre; San Gabriel, en el que fueron Benjamín, Guillarm, Delisle (fallecido en el trayecto) y Basugnar; y el San Juan Bautista, que llevó a Bernardino, Panal, Ambrosio Noasy, Agapito y Pertero. En la documentación oficial el contingente fue asentado por "familias", encabezadas por 19 hombres, y comprendían a 42 mujeres y 17 niños; la lista de "criados" apuntaba 30 hombres, 27 mujeres y 1 niño, un total de 136 personas subdivididas en 78 “amos" y 58 sirvientes. ${ }^{13}$

Para el viaje se acordó socorrer con cien pesos al líder negro y con cincuenta pesos a cada uno de sus subalternos hasta el número de once, para adquirir algunos utensilios que creyesen indispensables. El dinero fue entregado a Ignacio Acosta, capitán ayudante de la plaza y conductor del grupo hasta España. ${ }^{14}$

Conocida su inminente llegada a Cádiz las autoridades del puerto estuvieron en estado de alerta y desconfianza hacia ellos. Se le ordenó al gobernador gaditano, el conde Cumbre Hermosa, que ubicara a todos en una casa, observando su conducta y tratando de conocer sus planes, encargando su cuidado al ministro de la Real Hacienda, don Antonio de Cabrera. Asimismo, se indicaba la inconveniencia de su permanencia en Europa, y también el de su envío a Madrid. ${ }^{15}$ La Corona no quería que los negros se quedasen en la Península sino regresarlos lo antes posible a tierras americanas, por lo que se ordenó al juez de arribadas de Cádiz, aún antes de que los emigrados llegasen al puerto, que dispusiese en la ocasión más oportuna su embarque en las naves, fueran mercantes o de guerra, que salieran para ultramar. ${ }^{16}$

Los barcos reales al mando de don Gabriel de Aristizábal llegaron en marzo de 1796, y debido a la idea de su estancia provisional a los Auxiliares no se les asentó en los registros de

12 GONZÁLEZ BETRÁN, Manuel: "Legislación sobre extranjeros a fines del siglo XVIII", Trocadero, núm.8-9 (19961997) pág. 114; IGLESIAS RODRÍGUEZ, Juan José: Una ciudad mercantil en el siglo XVIII. El Puerto de Santa María, Sevilla, Universidad de Sevilla-Fundación Municipal de Cultura de El Puerto de Santa María- Muñoz Maya y Montraveta (eds.), 1991, págs. 583-584.

13 Archivo General de Indias (en adelante, AGI.) Estado, 3, No.10. Estado que manifiesta las familias que de los negros caudillos se han embarcado en los buques de S.M. Habana a 22 de enero de 1796.

14 Archivo Museo Álvaro Bazán (en adelante, AMAB). Exp. a Indias, leg. 21 (18/177). Sobre las tropas auxiliares de Santo Domingo. La Habana a 23 de enero de 1795.

15 AGI. Estado, 3, No.10. Real Orden dada en Badajoz a 12 de febrero de 1796; AGI. Estado, 3, No.10. Carta al gobernador de Cádiz proveniente de Manzanares a 20 de marzo de 1796.

16 AGS. S.G. leg.7161, exp. 24. El capitán general da cuenta de los jefes y negros auxiliares que han llegado a la plaza de La Habana. 11 de enero de 1796. 
entradas de vecindario y transeúntes de ese año. Asimismo, a pesar de que la permanencia se prolongó, tampoco aparecen en el censo poblacional de $1801 .{ }^{17}$

Al arribo de las antiguas Tropas Auxiliares, Cumbre Hermosa dispuso que se les diese una cantidad de dinero en calidad de socorro. Al mes siguiente se señalaba que los ex aliados recibirían las mismas pagas que en América con la diferencia de tener entonces pesos sencillos por pesos fuertes, por lo que ésos elevaron sus protestas ya que lo suministrado no les alcanzaba para mantener a sus familias y sirvientes. ${ }^{18}$ Poco después el gobernador dispuso que a Juan Francisco se le asignaran 350 pesos sencillos; a Benjamín 160 pesos; a Bernardino 100 pesos; a Pablo Mecurio 40 pesos; a Guiron, Baragnar, Ricard, y Ambrosio 30 pesos; a los ayudantes Lefebre y Watable 20 pesos cada uno; a Carrer, Agapito y Pero 20 pesos; para Santiago Marcille, Hugue, Francisco, Pedro y Mauricio 15 pesos, y 10 pesos para Mandé. En total, la suma ascendía a 955 pesos. Esa cantidad debía servir para mantener a las 142 personas que eran ya debido a siete nacimientos recientes. ${ }^{19}$

La familia de Juan Francisco se conformaba por Ana, su madre, su esposa Maria Josefa (en otros documentos aparece como María de la Asunción de Milo, a pesar de ser la misma persona), y sus hijas Celestina y Maria Josefa. También le acompañaron su hermana María Luisa y Ángela, la nieta de ésta; y la prima Adelaida y su hija Feliciana. ${ }^{20}$

La presencia en Cádiz del general de color -grados militares que los negros se autoasignaron según su jerarquía y que sus aliados hispanos les respetaron pero nunca oficializaronacompañado de su numerosa comitiva, además de ser llamativa entre otras cosas porque Juan Francisco y "un inspector" (Bernardino tal vez) portaban uniformes e insignias de oficiales generales, no resultó grata para las autoridades, quienes buscaban otro destino para el antiguo y ex "amadísimo" aliado. ${ }^{21}$ De tal forma, Manuel Godoy propuso destinarlos a Puerto Rico u otra de las posesiones que no fuesen Cuba o Trinidad. ${ }^{22}$

Después de un tiempo de vigilancia el gobernador de Cádiz informaba al Consejo que la conducta del líder había sido hasta ese momento razonable y moderada, y que lo que deseaban los negros era que se les proporcionasen tierras para cultivar y poder mantener a sus familias, y que ello sirviese de recompensa tanto por sus servicios a la Corona como por el abandono de "las propiedades" en Santo Domingo. Juan Francisco escribió a la autoridad gaditana señalando que aquello era necesario ya que se les pagaba en pesos sencillos, carecían de labranza y tenían problemas para comprender la lengua española. Cumbre Hermosa apoyaba la opinión señalada con anterioridad por el Consejo sobre la imprudencia de mantener en Europa a aquellos negros, por lo que aconsejaba su remisión a América, pero a regiones continentales pues en las islas se podría considerar arriesgado su envío por el crecido número de gente de color en ellas, a pesar de que los Auxiliares pidieron en alguna ocasión su envío a Trinidad. ${ }^{23}$ Para evitar eventuales problemas de insurrección el

17 Archivo Histórico Municipal de Cádiz (en adelante, AHMC.) Caja 4047, exp.27. Vecinos. Nueva entrada del año de 1796. Abecedario general de todas las naciones; AHMC. Caja 4047, exps.23, 26 y 27. Franceses. 1796; AHMC. Libro 1029. Ciudad de Cádiz. Padrón General de su vecindario. Cádiz a 25 de agosto de 1801.

18 AGI. Estado, 3, No.10. El conde de Cumbre Hermosa da cuenta de lo señalado por Real Orden. Cádiz a 18 marzo de 1796; AGI. Estado, 3, No.10. Carta del Conde de Cumbre Hermosa a Manuel Godoy. Cádiz a 6 de abril de 1796.

19 AGI. Estado, 3, No.10. Relación de los oficiales negros procedentes de las tropas de auxiliares de Santo Domingo. Cádiz a 4 de abril de 1796

20 Ibid.

21 AGI.Estado, 3, No.10. El conde de Cumbre Hermosa da cuenta de lo señalado por Real Orden. Cádiz a 18 marzo de 1796.

22 AGI. Estado, 3, No.10. Sobre estancia en España del caudillo Juan Francisco. 1796. En el documento se señala lo arriesgado de enviar a los negros a las islas, en virtud de su posible convivencia con los de color allí asentados.

23. AGI. Estado, 3, No.10. Carta del conde de Cumbre Hermosa a Godoy. Cádiz a 6 de abril de 1796. 
gobernador recomendó separar a las familias, sobre todo las de los principales, y distribuirlas a bastante distancia entre sí para impedir toda correspondencia. ${ }^{24}$

Sobre la presencia de los numerosos negros en Cádiz el gobernador no manifestó recelo alguno por parte de la población, aunque indicó que habían despertado "curiosidad y admiración por la extrañeza de los personajes", pero también señaló que con el tiempo las circunstancias pudiesen cambiar al igual que el pensamiento y postura de los habitantes hacia los recién llegados. ${ }^{25}$

La situación económica de Juan Francisco no fue la que él soñó tras su adhesión al bando hispano. Incluso había contraído una deuda de 850 pesos con diversas tiendas de la ciudad por la compra de víveres, socorros para su familia y demás individuos que le acompañaron en el viaje. El jefe de color solicitó que el gobierno saldara lo que debía alegando que su sueldo era "raquítico", y que también era imposible que sus segundos vivieran sin su ayuda. Para tratar de paliar un tanto la precariedad sacó de la Aduana la plata labrada que llevó en el viaje y fue vendiéndola, debiendo satisfacer los derechos de venta que ascendieron a 981 reales de vellón, por lo que también pidió que el rey se los perdonase. El soberano no accedió, aunque se comprometió a saldar la deuda anterior ${ }^{26}$ Este es el único dato con que se cuenta referente a ese metal ya que, al igual que las cajas con municiones que Juan Francisco olvidó en el barco en La Habana, no se refleja en el registro de muebles y objetos que se le permitió transportar de Santo Domingo a Cuba. ${ }^{27}$

El destino final de los negros aun no estaba decidido debido a la falta de acuerdo entre las dos partes. Godoy pensó entonces remitirlos a Ceuta, por lo que se le pidió su opinión a Juan Francisco. Se le dijo que ese destino sería provisional hasta que pudiesen restituirse a América, con el goce en ese sitio del sueldo de "su graduación". Después de una vacilación, la contestación del jefe negro fue negativa y la argumentaba por su preferencia hacia Cádiz, aunque se conformaría, mientras tanto retornaban a ultramar, con vivir en otro lugar de Andalucía, con el pago y el respeto a las graduaciones a todos sus oficiales. ${ }^{28}$

Ante la preferencia de los Auxiliares de partir a tierras americanas, Ignacio Acosta opinó que, a pesar de la existencia de numerosos negros esclavos, las costas de Caracas y Cartagena le parecían los mejores lugares para el establecimiento de los negros porque en esos puntos sería fácil dividirlos e impedir su comunicación y trato con la gente de color de las islas. ${ }^{29}$

Buscando alguna solución al problema y a la "resistencia de Juan Francisco", el rey mandó preguntar al jefe de los negros por medio del gobernador de Cádiz, "me digan qual [sitio] les acomodará mas", aclarando que no esperasen recibir los sueldos que gozaban en el día, ya que serían rebajados y que en el sitio de su elección se ocuparían en algo provechoso. Enterado Juan Francisco, pidió permiso para pasar a Madrid "para tener el honor de besar las manos del Rey", pero le fue denegado aduciendo que causaría "novedades" en la corte, pero que de todas maneras a través del gobernador el soberano siempre lo podía atender. ${ }^{30}$

24 AGI. Estado, 3, No.10. El gobernador de Cádiz al Consejo. Cádiz a 9 de mayo de 1796.

25 Ibid.

26 AGI. Estado, 3, No.10 (16). Carta de Cumbre Hermosa al Príncipe de la Paz. Cádiz a 13 de junio de 1796; AHN. Estado, leg.574. (2). Sobre el jefe de negros auxiliares Juan Francisco. Cádiz a 28 de junio de 1796.

AGI. Estado, 3, No.10 (12a). Ettate des muebles et effets du general Jean François, mette a L'Havane.

28 AGI. Estado, 3, No.10. Carta del conde de Cumbre Hermosa a Godoy. Cádiz a 28 de julio de 1796. Si hubo intención de Juan Francisco de ir a Ceuta, incluso hablaba de 120 personas que deseaban ir a ese sitio, sin embargo posteriormente la respuesta fue negativa, AHN. Estado, 574 (4). Carta de Juan Francisco a Godoy. Cádiz a 30 de julio de 1790.

29 Ibid. La propuesta de Caracas pudo estar fundada en la idea que se tuvo años antes de llevar negros a la región, AGI. Venezuela, leg.481. Proyecto para la introducción de negros para el trabajo más barato. 1786.

30 AGI. Estado, 3, No.10. Carta de Godoy al gobernador de Cádiz. San Ildefonso a 9 de agosto de 1796; AGI. Estado, 3 , No.10. Carta de Cumbre Hermosa a Godoy. Cádiz a 10 de agosto de 1796. 
Ante el rechazo de Ceuta, el sitio elegido por los negros fue entonces Jerez de la Frontera, donde, según apuntaban, harían fielmente el servicio que el rey les ordenase pero indicando que únicamente conocían el cultivo de los frutos de su isla. ${ }^{31}$ Sin embargo, poco después de nuevo pedían que los dejasen en Cádiz "hasta que [...] sean transportadas a America" ${ }^{32}$

Mientras tanto Juan Francisco seguía manifestando que su asignación era corta. Sin duda esperaba una suerte mejor, un alza en su retribución económica, o un empleo mejor pagado, ya que alardeaba de que

“(...) el capitan general de Santo Domingo no ha parado de mandar a la Corte mis trabajos, mis hechos, mis expediciones, y mis conquistas, como me lo ha siempre repetido en sus correspondencias. V.E. tomando nuestra suerte y nuestros derechos en consideración, podra exilar en nuestras personas la piedad y la generosidad del Rey Vuestro Amo para que veamos a cumplirse la promesa del Capitan General de Santo Domingo echa por el antes dicho en el nombre de S.M. de acercarnos de su trono y humillarnos a sus pies, y obtener un fin dichoso a la suerte de una tropa de familias en las ultimas miserias que sin algun credito fueran pedidos (...)" 33

En octubre siguiente, y después de mencionarse de nuevo a Puerto Rico como probable lugar de destino, se tomó la determinación de enviar a los negros a la Costa de los Mosquitos, en la Capitanía general de Guatemala. ${ }^{34}$ No obstante, ese viaje, así como algunos intentos posteriores, no se llevó a cabo -en este caso por la inminente guerra contra Inglaterra-, y las antiguas tropas permanecieron en Cádiz. ${ }^{35}$

Debido a que la autoridades no reconocían el grado de general que decía tener, en julio de 1798 Juan Francisco solicitó al rey le concediese el de Teniente general ya que insistía en que ése le fue concedido por el Comandante General de la Escuadra de America don Gabriel de Artizabal, quien también otorgó otros a sus acompañantes con sus respectivas divisas. ${ }^{36} \mathrm{Al}$ caso, mientras el contingente de negros navegaban a Cádiz, Juan de Herrera escribió a bordo del navío San Gabriel que el presidente de Santo Domingo, "por razones que hallaría convenientes", condecoró a los jefes en los términos más distinguidos otorgándoles las respectivas insignias, en lo que lo imitó Aristizábal, y su segundo jefe, don Francisco Xavier Muñoz. ${ }^{37}$ Esto indica que lo señalado por Juan Francisco sobre su título era verdad, o al menos eso le hicieron creer. Sin duda que García y Aristizábal respetaron el grado autoasignado primero y condecoraron después a Juan Francisco, pero fue en el marco de lograr y mantener su simpatía y fidelidad, nunca con el objetivo de otorgarle un reconocimiento firme.

No obstante las quejas de las autoridades españolas sobre los títulos que utilizaban los negros y la duda de su validez, en la documentación elaborada cuatro meses después de la solicitud de Juan Francisco se mantenían esos rangos militares. Así, se indicaba que los "oficiales"

AGI. Estado, 3, No.10. Carta de Cumbre Hermosa a Godoy. Cádiz a 28 de agosto de 1796.

AGI. Estado, 3, No.10. Carta del conde de Cumbre Hermosa a Godoy. Cádiz a 7 de octubre de 1796.

AHN. Estado, leg.574 (2). Sobre el jefe de negros auxiliares Juan Francisco. Cádiz a 22 de agosto de 1796.

AGI. Estado, 3, No.10. Carta de Godoy a Miguel de Azanza. San Lorenzo a 17 de octubre de 1796; AGS. S.G. leg.6936, exp.24. Carta al capitán general de Guatemala. San Lorenzo a 25 de octubre de 1796.

35 AGS. S.G. leg.7161, exp.33. Relación de los oficiales negros de las tropas auxiliares de Santo Domingo. Cádiz a 16 de noviembre de 1798; GEGGUS, David: Haitian Revolution Studies, Indiana University Press, 2002, pág. 199.

36 AGI. Estado, 3, No.10. Carta de Don Juan de Álvarez al secretario del despacho de Estado. Palacio a 27 de julio de 1798 .

37 AMAB. Exp. a Indias, leg.21 (18/177). Sobre las tropas auxiliares de Santo Domingo. A bordo del navío San Gabriel al anclar en el puerto de la Habana a 25 de enero de 1796. 
negros y familiares que permanecían en Cádiz ascendían a 122 individuos (40 menos que el año anterior, tal vez por fallecimiento), comenzando la lista con el "teniente general Juan Francisco", seguido del mariscal de campo Benjamín, el inspector Bernardino, el brigadier Pablo Mercurio, el coronel y comandante Joaquín Baagnac, los coroneles Ambrosio Noyse, Pedro Guillaume, Francisco Agapito, Pablo Ricard, Antonio Lefebre, los capitanes José Watabe, Bruno José, Juan Carlos Carrer, Santiago Marseille, José Augusto Francisco y Ramón Hugue, y el teniente Nicolás Preau. ${ }^{38}$ Incluso dos años más tarde, el 23 de febrero de 1800, se informaba del fallecimiento en Cádiz del mariscal de campo Benjamín, mencionándosele como "residente de esta plaza" ${ }^{39}$ Por el contrario, en el caso de la petición de la pensión para la viuda de Juan Francisco en la misiva fechada en 1806 se le señala únicamente como "Xefe que fue de los Negros auxiliares". ${ }^{40}$

Insistiendo en su crítica economía, firmando ya como Juan Francisco Petecou, escribió una carta en 1803 desde Cádiz al gobernador de Cuba señalando que en varias ocasiones había mandado mensajes al antiguo ministro de finanzas reales de Bayajá, don Juan Sánchez, sin obtener respuesta. En la comunicación exigía tener noticias de su equipaje que hacía ocho años le habían retenido en la Aduana de La Habana, así como del valor de los caballos, reses y mulas de su propiedad que se habían vendido a la República francesa después de su salida de Bayajá y que el entonces gobernador Casa Calvo, como vendedor del ganado, le debía resguardar. Señalaba que otros sujetos que le debían dinero eran: el padre José Vázquez, procedente de la venta de diecinueve caballos y Ramón Alderete, capitán del regimiento de dicha plaza a quien dejó un joven negro y un caballo de maestranza para ofertar. Juan Francisco apuntaba que por sus problemas económicos reclamaba el dinero de las prendas dejadas para vender en Santo Domingo, así como de la valija retenida. ${ }^{41}$

La carta del antiguo jefe negro desvela las relaciones comprometedoras de individuos que se valieron de él para obtener algún beneficio. Es reflejo también del comercio de personas que Juan Francisco desarrollaba en la isla y de las consideraciones de que gozaba, permitiéndosele la venta de caballos que debió obtener en batallas. De la solicitud de Petecou no tenemos informes posteriores. ${ }^{42}$

Su situación económica debió de complicarse por el brote de la fiebre amarilla que fue declarada en el verano de 1800 , y que duró hasta finales de 1804, diezmando a la población en sus niveles demográficos, sin que se tenga informe alguno sobre el grado de afección en ese grupo de negros. ${ }^{43}$ Asimismo, las dificultades de los Auxiliares pudieron recrudecerse en la segunda mitad de 1805 tras el mandato real de restringir todo tipo de pago de sueldos en el departamento gaditano, con excepción de goces personales y sueldos de oficiales, debido a la

38 AGS. S.G. leg.7161, exp.33. Relación de los oficiales negros de las tropas auxiliares de Santo Domingo. Cádiz a 16 de noviembre de 1798. A esta cifra hay que considerar los nacidos durante esos años por lo que no todos los censados estuvieron en Santo Domingo.

39 AGS. S.G. leg.7162, exp.23, No.110. Carta del consejo al Capitán general de Andalucía. Aranjuez a 20 de marzo de 1800 .

40 AGI. Santo Domingo, leg.1039. Oficios del ministerio de guerra concediendo pensión a María Asunción, viuda de Juan Francisco Petecu. San Lorenzo a 25 de octubre de 1806.

41 AGI. Estado, 3, No.10. Carta de Juan Francisco al gobernador de Cuba. Cádiz a 10 de mayo de 1803.

42 Pamphile Lacroix, un general que estuvo en Santo Domingo a principios del siglo XIX, escribió Memories pour servir a l'histoire de la revolution de Saint Domingue (2 vols., Paris, 1819, revisado en 1829), señala que Juan Francisco se enriqueció con el pillaje que realizaba durante los combates, Cit. en SCHOELCHER, Víctor: Vie de Toussaint, París, Edition Karthala, 1982, pág. 41.

43 DE AREJULA, Juan Manuel: Breve descripción de la fiebre amarilla padecida en Cádiz y pueblos comarcanos en 1800, Imprenta Real, Madrid, 1806, págs. 156-435-439; IGLESIAS RODRÍGUEZ, Juan José: La epidemia gaditana de fiebre amarilla de 1800, Cádiz, Diputación de Cádiz, 1987, págs. 31-54. 
falta de caudales. ${ }^{44}$ El último dato de asignación alguna con que se cuenta por ahora, señala que para fines de 1806 cada una de "las familias de dicha Isla" de Santo Domingo asentadas en Cádiz, gozaban de una pensión de cuatro reales. ${ }^{45}$

\section{LA MUERTE DE JUAN FRANCISCO PETECOU.}

Sobre el lugar y año del fallecimiento del ex líder negro existen dudas. Se ha señalado que sucedió en Cádiz en 1806; ${ }^{46}$ que el jefe negro residió en España hasta su muerte, ocurrida en 1811, o que residió en Madrid con las mayores comodidades. ${ }^{47}$ Otras opiniones apuntan únicamente que murió en la Península sin especificar lugar. ${ }^{48}$ Unas más señalan que Juan Francisco falleció en Cádiz donde logró amasar una gran fortuna, rodeado de los favores de numerosas mujeres blancas y conviviendo con lo mejor de los círculos sociales ${ }^{49}$ que murió en 1820 mientras ocupaba el puesto de gobernador de Orán, designación que España le dio por sus servicios a la Corona ${ }^{50}$ hipótesis imposible ya que esa plaza fue abandonada por España en 1792; que falleció rico y con honores en el puerto gaditano en $1810 ;{ }^{51}$ que terminó sus días en la Costa de los Mosquitos ${ }^{52}$ o que regresó a Haití. ${ }^{53}$ La tesis más reciente indica que el 16 de septiembre de 1805 es la fecha de la desaparición física de Juan Francisco. ${ }^{54}$

Ante tales incertidumbres el lugar y fecha del fallecimiento de Juan Francisco no se sabe con certeza. Sin embargo, la última puede ser cierta ya que a su viuda, citada como María de la Asunción de Milo, se le concedió una pensión de cuatro reales el 29 de agosto de 1806, similar a la de las otras familias de Auxiliares. Sin embargo a la mujer le debió resultar poca la pensión ya que al mes siguiente, el 23 de septiembre, solicitó que fuese extensiva a sus hijas María Josefa y Celestina, a sus sobrinas Alfonsina de Roulo y Victoria Claret, y a sus nietos Juan Antonio, Francisco Ramón y Ángela Boranges. El rey determinó que a todas esas personas se les abonasen cuatro reales de vellon diarios. ${ }^{55}$ La extensión de la pensión para otras personas, incluidas a las hijas ya casada, y para

44 AMAB. Real Orden, leg.6559, carpeta 8. Real Orden. San Lorenzo a 18 de octubre de 1805.

45 AGI. Santo Domingo, leg.1039. Oficios del ministerio de guerra concediendo una pensión a María de la Asunción de Milo, viuda de Juan Petecu. San Lorenzo a 29 de agosto y 25 de octubre de 1806.

46 DEIVE, Carlos: Las emigraciones dominicanas a Cuba (1795-1808), Santo Domingo, Fundación Cultural Dominicana, 1989, pág. 127.

47 FRANCO, José Luciano: Revoluciones y conflictos internacionales en el Caribe, pág. 42; FRANCO, José Luciano: La conspiración de Aponte, La Habana, Publicaciones del Archivo Nacional de Cuba, 1963, pág. 10.

48 AIMÉ, Cesaire: Toussaint Louverture: La revolución francesa y el mundo colonial, La Habana, Academia de Ciencias de Cuba, 1967, pág. 255; DI TELLA, Torcuato: La rebelión de esclavos de Haití, Buenos Aires, Ediciones de IDES, 1984, págs. 73,85 .

49 KORNGOLD, Ralph: Citizen Toussaint, Connecticut, Greenwood Press Publishers, 1979, pág. 116. Este autor señala que Juan Francisco vestía con elegantes y ricos uniformes con elementos de oro.

50 ALEXIS, Stephen: Black liberator. The life of Toussaint Louverture, London, 1949, pág. 76.

51 BENOT, Yves: La revolution francaise et la fin des colonies, París, Editians La Découverte, 1987, págs. $263-264$.

52 VON GRAFENSTEIN, Johanna: Nueva España en el Circuncaribe, 1779-1808. Revolución, competencia imperial y vínculos intercontinentales, México, Universidad Autónoma de México, 1997, pág. 266. Esta postura ha sido seguida por otros autores, por ejemplo REY, Nicolas: "Caribes noirs et "negros franceses" (Antilles/Amérique centrale). El périple de Noirs “révolutionnaires”, Nuevo Mundo Mundos Nuevos, núm..5 (2005), págs.1-3, http://nuevomundo.revues.org/document 315.html. En su trabajo Rey, aunque no trata sobre la muerte de Juan Francisco, da por certero que esa ocurrió en Guatemala, donde indica que entrevistó a sus descendientes. Más que ser familiares directos del líder, la gente que señala el investigador debieron recurrir a la figura de aquel negro de Saint-Domingue en buscar una identificación histórica.

53 HOUDAILLE, Jacques: "Negros Franceses en América Central a fines del siglo XVIII", Revista Antropología e Historia de Guatemala, núm.1 (1954) pág. 68.

54 GEGGUS: Haitian Revolutionary Studies, pág. 294, nota 103, apunta una comunicación personal de A. Crouzet.

55 AGI. Santo Domingo, leg.1039. Oficios del ministerio de guerra concediendo una pensión a María de la Asunción de Milo, viuda de Juan Petecu. San Lorenzo a 29 de agosto y 25 de octubre de 1806. 
las sobrinas, hace pensar que el justificante de la solicitud de la viuda Petecou se basó, no tanto en una situación precaria, sino en la figura de Juan Francisco como aliado de importancia en el pasado y en las promesas reales de 1793 ofrecidas por el soberano para lograr su adhesión. ${ }^{56}$

La prensa de la época no se ocupó de la noticia de la muerte de Juan Francisco, y tal vez los intentos de separación de los Auxiliares de otros grupos de negros dieron frutos.

Ya sin la fuerza de la imagen de su jefe, los negros Auxiliares parecieron desmoronarse y la documentación ya no da indicios de una lucha por mantener o lograr algunas prerrogativas como lo había hecho Juan Francisco. Sin embargo, debió existir una persona designada para dirigir o mantener el control dentro del grupo, asunto que se deduce por el hecho de seguirse utilizando la jerarquía militar entre los negros de Santo Domingo, incluso en $1810,{ }^{57}$ o para tener contacto con las autoridades debido a la prohibición que se les hizo en marzo de 1813 de poder marchar a ultramar, a pesar de ser libres,$^{58} \mathrm{o}$ para organizarse para hacerlo tras el levantamiento de ésa pocos meses después. ${ }^{59}$ Para esas situaciones se debió de contar un cabecilla que mantuviese el control interno de los Auxiliares en Cádiz

\section{LOS AUXILIARES, LAS CORTES DE CÁDIZ Y SU SALIDA DE LA PENÍNSULA}

La presencia en Cádiz de aquellos negros no fue olvidada por las autoridades que tampoco habían desistido de la primaria idea de remitirlos a tierras de América. Así, quince años después de su arribo, el 22 de julio de 1811 se hacía la mención que en pocos días partiría hacia La Habana la fragata mercante La Oliva y que embarcaría a sesenta o setenta de los antiguos rebeldes de Santo Domingo, con destino a esta isla y a la de Puerto Rico. A algunos representantes de Cuba en las Cortes de Cádiz les parecía inapropiado el envío a América de esos negros ladinos, ya que habían conocido la libertad o combatido por ella, que habían vivido en aquella ciudad los debates de las Cortes sobre la libertad de imprenta y de los derechos de todos los hombres, excepto de los negros sojuzgados y de la mayoría de los libertos descendientes de africanos. Para evitar algún "contagio", el diputado de Cuba en Cortes Andrés de Jáuregui, representante de los esclavistas propuso su envío a las islas Baleares o a las Canarias. ${ }^{60}$

El 8 de julio de 1812 se mandó decir que los Auxiliares y otros negros podían ser mandados a ultramar, pero en marzo siguiente se revocó el mandato exclusivamente para los antiguos aliados. ${ }^{61}$

A pesar de no contar con documentos que avalen alguna situación especial derivada de la presencia de los Auxiliares en el puerto donde se debatía la Constitución Española, y a pesar del temor de algunos diputados, sobre todo de los cubanos, en junio de 1813, al año siguiente

56 En una carta del 21 de abril de 1802, dirigida al su mariscal Juan Jaque del grupo de Auxiliares enviado a Trujillo, Juan Francisco señaló que su hijas se habían casado "Lesette (sic) con Lefebre y Celestina con Carrere", e indicó la muerte de su hermana María. Archivo General de Centro América. A.1. IR, leg.51, exp. Honduras. Sobre el establecimiento en Matiare. Guatemala a 22 de diciembre de 1802.

57 AGI. Santo Domingo, leg.1099. Carta de Rafael Orozco a don Nicolás María de Sierra. Cádiz a 29 de agosto de 1810

58 AGI. Santo Domingo,leg.1099. Documentos varios sobre la petición de Juan Sañan. Cádiz, del 30 de mayo al 2 de julio de 1813 .

59 AGI. Santo Domingo, leg.1099. Copia de carta del ministerio de guerra al capitán general de Cádiz. Cádiz a 6 de junio de 1813 .

60 Archivo Nacional de Cuba. Donativos y remisiones, leg.521, exp.22, Cit. en PIQUERAS, José Antonio: "Leales en épocas de insurrección. La élite criolla cubana entre 1810 y 1814 ", Visiones y revisiones de la Independencia Americana, (2003) págs. 203-204.

61 AGI. Santo Domingo,leg.1099. Documentos varios sobre la petición de Juan Sañan. Cádiz, del 30 de mayo al 2 de julio de 1813 . 
de haberse promulgado la Constitución, la Regencia tomó la decisión que habría de cerrar un largo período de inestables relaciones entre la Corona y esos súbditos de color, y mandó que se aprovechasen todas las ocasiones oportunas de embarcar aquellas familias de negros para América. ${ }^{62}$

Con esa indicación, se dieron las primeras salidas de los Auxiliares de Cádiz con destino a la Costa de los Mosquitos y Puerto Rico, en diciembre de ese año. El viaje para el primer sitio, compuesto de seis personas (cuatro mujeres y dos hombres), tocó tierras boricuas y debido a la inexistencia de barcos que fuesen directamente a Honduras o al menos a Campeche, los viajeros debían ir primero a La Habana y de ahí a Centroamérica. El principal de ellos, Francisco Agapito, pidió entonces pasar a Santo Domingo para establecerse, con lo cual esos negros no llegaron a la Costa de los Mosquitos. ${ }^{63}$ En abril de 1814 salieron de Cádiz rumbo a Puerto Rico siete personas del grupo de Auxiliares (cuatro mujeres y tres hombres), pero al llegar a esa isla el gobernador sin excusa alguna los envió a Cuba. ${ }^{64}$

El tornaviaje de los Auxiliadores tampoco fue lo que ellos esperaban, y terminaron -tal vez la mayoría- dispersos por diversas islas y tierra continental, cuando no buscando la manera de permanecer en la Península, asunto éste que no se ha podido confirmar.

\section{CONSIDERACIONES}

La estancia de los Auxiliares en el puerto gaditano debió de convertirse con el tiempo en algo semejante a un olvido concertado por las autoridades. Si bien se les pagaba un salario o asignación por sus antiguos méritos para con la Corona española -lo que inútilmente se le trató de quitar-, las promesas hechas para ganar su adhesión años antes quedaron lejos de ser lo que los negros y su jefe vivían. A diferencia de lo escrito por algunos autores, el antiguo y arrogante general de las Tropas Auxiliares -y por ende éstas- terminó su existencia en una situación de precariedad, sin distinción alguna y segregado de la sociedad por sus antecedentes bélicos y condición social. A pesar de ello, no deja de llamar la atención lo permisivas que fueron las autoridades españolas con él, sobre todo por su confrontación con ellas en cuanto a sus destinos de envío, y también por el hecho de llevar consigo alguna cantidad de plata, probablemente producto de pillaje.

La desconfianza hacia los negros por parte de las autoridades hispanas fue patente desde su llegada, y en espera de que se cumpliese la orden de enviarlos a otra parte del imperio no se les registró en la arribada al puerto, tampoco aparecían en el censo de población de años posteriores, y, a pesar de su experiencia, no fueron requeridos para las batallas que España libraba en Europa o África, o contra los ingleses en la propia Cádiz en 1797. A pesar de ello, a Benjamín se le mencionó como residente en 1800, y a otros negros como "residentes" en 1810. Geggus señala que salvo el general Laplume, cuya fecha de defunción no conocemos, ninguno de los Auxiliares aparece en el registro del cementerio municipal de Cádiz. ${ }^{65}$

El jefe negro sentía responsabilidad en la manutención de la gente que había viajado consigo a España. Pero en el mismo caso habría que preguntarse a qué respondía esa preocupación, si a una conciencia de grupo para mantenerse unidos, o al miedo a perder su liderazgo y con ello su papel de interlocutor con los españoles y de ciertos beneficios que pudiese obtener con ello.

62 AGI. Santo Domingo, leg.1099. Copia de carta del ministerio de guerra al capitán general de Cádiz. Cádiz a 6 de junio de 1813 .

63 AGI. Santo Domingo, leg.964. Carta de Agapito al rey. Santo Domingo a 24 de mayo de 1815; DEIVE: Las emigraciones dominicanas, págs. 126-127.

64 AGI. Cuba, leg. 1827; DEIVE: Las emigraciones dominicanas, pág. 127.

65 GEGGUS: Haitian Revolutionary Studies, pág. 294, nota 103. 
Las Cortes Generales en Cádiz con su lucha parlamentaria sacó a relucir la situación que aquel grupo de Auxiliares había jugado en los intereses del pasado, que después de prestar su ayuda y haberles prometido la libertad, no sólo se les quitaba ésta sino que también su honra por la precaria situación en que se encontraban en el puerto. A la negativa de su permanencia en la Península se contraponía la postura de los representantes de los esclavistas, sobre todo de Cuba, que utilizando como factor de manipulación el recuerdo de Haití, impidieron que esos negros que ya habían visto otras formas de convivencia fuesen remitidos a aquella isla. Sin duda entonces que la presencia de los Auxiliares de Santo Domingo y sus descendientes en la plaza gaditana, influyó en los debates parlamentarios.

Pero a pesar de la manipulación de "lo haitiano" y de las voces en contra pudo más el interés de la Regencia por deshacerse de esos incómodos ex aliados y pretextando que "la experiencia ha hecho ver son mayores los inconvenientes que ofrece la permanencia de los Morenos auxiliadores de Santo Domingo en esta Plaza", permitió su salida hacia América a mediados de 1813, aunque no se tienen referencias de cuántos lo hicieron. Aquella decisión debió ser pensada de antemano pero debido a los conflictos que se dieron en las Sesiones de Cortes se dio a conocer hasta al año siguiente de la promulgació de la Constitución. Con ello se dio oficial término a esa embarazosa situación -y de la alianza entre el grupo enviado a Cádiz y las autoridades-, que tras el fracaso en la contienda contra Francia resultó incómoda para España, y que pasaría por llevar a la Península a uno de los cabecillas del inicio de la revolución de negros esclavos de Saint-Domingue. 